\title{
Training U.S. Managers for Distant Shores
}

\author{
Yezdi H. Godiwalla ${ }^{1}$ \\ 1 Management Department, College of Business and Economics, University of Wisconsin-Whitewater, WI \\ 53190-1790, USA
}

Correspondence: Yezdi H. Godiwalla, Management Department, College of Business and Economics, University of Wisconsin-Whitewater, WI 53190-1790, USA.

Received: June 27, 2017

Accepted: August 2, 2017

Online Published: September 13, 2017

doi:10.5430/ijba.v8n6p11

URL: https://doi.org/10.5430/ijba.v8n6p11

\begin{abstract}
Proper pre-departure training and post-arrival mentoring of US managers who are assigned for distant and culturally and operationally different countries are vital for their success in their foreign assignment. Training them for foreign assignments is vital because they will be overwhelmed by an onslaught of diverse challenges of their tasks and unfamiliar operating and cultural situations, all of which will confound even the most capable domestic manager. Supervisory and decision making situations will be different from the home country situations with which they are so used to working before they left for the foreign shores. Specifically, they must cope and better manage their personally challenging issues, which are their own personal anxiety and stress arising out of unfamiliar situations that defy the cause-effect logic they were used to in their home countries, the foreign country's unfamiliar environment causing perceived environmental uncertainty, their own personal flexibility and adaptation, communicating and leading with empathy in host country cultures, and self-efficacy and their own sustained drive for continuously working long hours to accomplish their own personal career goals and the foreign subsidiary's objectives.
\end{abstract}

Keywords: training expatriate managers, international management, and foreign assignment preparation

\section{Introduction}

Many US trained specialists or experts, particularly in a narrow specialized field, focus in their career on their own specialty in their own industry, such as cost accounting of the steel industry. They become known as experts in a narrowed domain. Their strengths in their "hard skills" are very good. They are often not as good in the "soft skills', such as consensus building, as in some other countries, such as Japan. They are focused on intense performance expectations within their own organizations and industry. When they are considered for foreign assignments in very different country cultures, these strong "hard skills" are a source of great strength because of their intense expertise. However, they need to adopt wider perspectives of other cultures of the other countries, particularly those which have very different systems and cultures.

Like the US specialists, many US managers are very goal and performance-oriented as they perform their leadership and other managerial roles. The intense competitiveness in their industry places further pressures on their continuous improvement and honing of their managerial expertise. They often operate in difficult and competitive task environments and they have to cope with the fast pace of work and the fast changing task environments.

A US specialist or manager who has primarily worked in his or her (henceforth "his" expressly means either "his" or "hers"; and, similarly, "he" or "she") US, domestic industry and environments, would have to significantly re-orient himself to the varying cultures of other countries where he may be posted. Moreover, the US manager or specialist bound for emerging market countries may find himself in even more different than the US domestic environment and, for him, even stranger environments of the very different culture, operating conditions, financial, supply chain, channel distribution systems, and the wider social and community systems. He has to keep on learning about the unfamiliar local cultures, in addition to his own foreign subsidiary's internal organizational workings and administrative policies and processes, markets and supply chain, and local economic and political and legal systems.

Further, and to a greater extent, he would feel lonely, even feel alienated. As a US person, he is alone and one of a kind, unless there are some other US people in his foreign organization. All other local people's eyes are on him, inside and outside the foreign organization, already placing him under greater scrutiny. This would be significantly mitigated if his spouse and children were with him so he may look forward to going to his residence after his work 
day in the foreign land. The overwhelming newness, or even strangeness, and uncertainty would place greater stress on him. He would really be more effective if he were better prepared for managing stress (higher than what he was used to in his US work situation and organization), learning to better adjust and communicate with the local peoples and foster greater networks and start enjoying his personal life in the local culture.

It is necessary for his organization to plan and organize his expatriate training programs before his departure and mentoring programs after his arrival in the foreign country. This would promote his adjustability in the initial period after an ease of entry into the foreign country. It would also better condition him for his new foreign assignment. Such training would include his ability to cope with his stress and raise his tolerance threshold; this is particularly challenging because he has to cope with the different countries' unfamiliar work and non-working environments. The unfamiliar task environments of the foreign subsidiary of the international organization create the need for greater efforts for adapting and flexibility. He has to manage in a different country culture and operating system. This means decision making, setting goals and priorities, leading, motivating, communicating, identifying and analyzing problems and situations and mastering the local logic of cause and effect so he becomes more adept and effective manager in the local context. The cultural distance between US and the foreign country generate an additional challenge to the US manager for learning the effective logic and method of decision making and being effective. He has to re-configure his own decision making, managerial, leadership, supervisory, communication styles and he has to keeping improving his own approaches to greater personal effectiveness in the local context and build greater self-confidence.

The challenge to the US expatriate, as an individual, takes place in many forms and it has many consequences, including: anxiety and stress because of unfamiliarity; ineffective problem solving, difficulty in managing cultural differences when it comes to communication and establishing working relationships; problems in personal adaptation; and not overcoming the obstacles achieving his or her full executive performance potential.

He has to evaluate and understand his own strengths and weakness profile as a specialist and manager, given his personality in the US. Then he needs to understand and take stock of the requirements of the foreign work and social situation, including the local organizational task environments. He needs to quickly learn the criteria of effective performance and he has to re-align his own methods to adopt these locally preferred approaches. The specific needs of the particular foreign assignment should be customized for the additional country-specific training content. In doing so, his training orientation would be better suited for the specific country's situation. This tailor-making approach would to determine the precise content of his training. Further, he needs to understand the cultural distance in specific terms between his U.S home country and the foreign country so that he can properly design the content and emphasis of his training for his social, cultural, supervisory and communication skills. Such "soft skills" training, together with cultural sensitivity training, would help him to have a smoother entry into the foreign social and work situation.

\section{The Scope of the Paper}

The training needs of US manager and specialist bound for a culturally different country (that is, culturally different from US culture) assignment is the topic of the paper. It explains how a US manager or specialist can specifically design his training program to suit the foreign country to which he is going. The challenge is greater when the difference in cultural and operating environments between the US manager and specialist's US home environment and the host country environment is wide and protracted. In the case of a widening cultural and operating gap between the two countries, the US manager and specialist would experience more extensive challenge in his foreign assignment (Selmer and Lauring, 2011). The paper takes the view that, given this extensive challenge likely to fall upon the US manager or specialist, well-developed, well executed pre-departure training and post-arrival mentoring programs would effectively meet the challenges of the US manager and specialist in his foreign assignment.

\section{Training the US Manager and Specialist}

Many US organizations use the US managers and specialists for the foreign postings, particularly at the very high levels. This is perceived to better ensure the injection into the foreign operations of US technical, operational, and administrative corporate approaches and philosophy of the organization. Zahra (2201) proposes a dual influence on an international organization's foreign subsidiary unit. It may often pressure a strong corporate strategic mandate, implying a strong focus on an HQ approved global strategic paradigm imperative. The other force is the influence of local environment of the host country and nearby regions that have an effect upon the MNC's foreign unit. In his study, Zahra (2001) found that both forces impose additional entrepreneurial expectation on the foreign subsidiary. This means the subsidiary would have to prospect for newer opportunities and deal with the issues of risks, threats and uncertainties emanating from the local (host country's and other nearby countries') environment. The US 
expatriate would thus perform the role of an entrepreneurial CEO or an entrepreneurial executive of the subsidiary unit and seek newer and better ways of doing business. He or she would more than ever be dealing with his own anxiety and stress in view of the perceived environmental uncertainty. Global competition continues to place increasing pressures on the international organization to manage their international operations more effectively. This poses challenges for international human resource management.

Foreign sales have become increasingly important for most international organizations. This is true as many emerging markets are booming in the developing world. Growth rates in these countries have outstripped those in industrialized countries. International organizations with expanding geographic scope thus need to better manage their foreign operations. The use of expatriates has become vital in the international organization's growth agenda. This places extra emphasis on more effectiveness of international managers and specialists, something that requires better attention to the expatriate's training. Luthans and Farmer (2002) explain the connection between increasing global competition and the greater need for expatriate training. They state the influence of increasing global competition: "As global competitive battles heat up, the importance of developing expatriate managers for international success should not be overlooked. In search of a competitive advantage, international organizations are increasingly devoting more attention and resources to cultural training as a way to improve job performance of their international assignees."

The use of expatriate managers would result in better foreign subsidiary performance, thus improved overall international organization's global competitiveness. Their knowledge of MNC's strategies and operating systems helps in focusing on competitive advantage. The offering of future scenarios of the foreign situation of the executive so that he may better focus on better honing his approaches for the foreign assignment ahead of time.

Many industrialized countries have cultures and operating environments vastly different from those of the developing countries. This wide gap poses a great challenge to the expatriate from countries such as US, UK, Germany and France. The expatriate has to be adaptable and self confident in dealing with this big difference. The Lee and Croker (2006) study concludes with these findings: "(1) the greater the expatriate confidence and his adaptability, then the lower is the perceived need for expatriate training; (2) the greater the complexity of task, the lesser the capability of host managers and the greater the cultural difference, then the greater is the perceived need for the expatriate's training; and (3) the expatriate's learning preference and the expatriate's instructor's training methods would determine the need for training and effectiveness of training."

\section{The Training Approaches}

Training the US managers and specialists is a way of preparing and conditioning the US personnel for the unfamiliar experiences that he may find himself in his foreign assignment. Such emotional and mental preparation is a worthwhile exercise for him as it would soften the sudden shock if he were not prepared at all. He should be pre-exposed to the kinds of issues and experiences which he may encounter as he steps in the foreign land and do his job. Pre-departure knowledge of the foreign assignment and other issues like living conditions become important content of training of the expatriate. The importance of such content of the expatriate training is reviewed by many studies. Chang (2005) has collected and combined the works of Tung (1982), Oddou (1991), Brewster and Pickard (1994), Zakaria (2000), and Petranek (2004). In that Chang (2005) explains, "Some of the more common features are cross-cultural training, communications (including language) training, clarification of performance criteria and expectation, cooperation and collaboration skills, managing stress and emotions, local logistics and everyday life issues, knowledge of the foreign subsidiary and its local environments".

As explained in the foregoing, the expatriate would be challenged in his first weeks and months in the foreign assignment. He would have to quickly adjust to the host country people and environment. Pre-departure training of cultural awareness and cultural sensitivity, communication in the local language, behavioral communication flexibility skills, stress reduction and management, newer approaches in solving problems in strange environments, and leading and motivating in different cultures are some of the more important training items. Shin, Morgeson and Campion (2007) further explain as they review other studies, "Communication competence, cultural empathy, interpersonal skills, and social interaction would improve cross-cultural adjustment to working and non-working environment".

While pre-departure training is emphasized in the foregoing, the US manager or specialist is facing the world alone in his foreign assignment. Thus, post-arrival mentoring by an experienced person is important too. Pre-departure and post-arrival training are both very important and they complement each other. Pre-departure training would condition the expatriate as to what he can expect in the foreign assignment. This training would help him to understand the host country culture, communication, methods of operation and way of life. However, the real impact that would 
overwhelm the expatriate is soon after he arrives in the host country. Here he has to muster all his own innate intelligence together with his applied training which he has received in his home country. Here the guidance of a mentor, who is experienced in the local professional and social issues and cultures, would be of great help. In this context of pre-departure training and post-arrival mentoring, Shin, Morgeson and Campion (2007) explain the advantages of the training and mentoring, "First, in the pre-departure stage, organizations select and train individuals for expatriate assignments. Second, in the post-arrival stage, when expatriate workers begin to interact with host country nationals (HCNs) and adjust their behaviors to the host country's cultural norms and values for better performance, behavioral cross-training can be implemented to ensure that expatriates behave in culturally appropriate ways. (Further), behavioral training is more effective in the post-arrival stage because expatriates tend to be more motivated to learn once they are in their assignments."

\subsection{Self-Assessment Process}

Regarding the self-assessment as an individual, the US manager or specialist has to analyze who he is and also how and why he has his likes, dislikes, preferences, biases, opinions, and assumptions about all aspects of his foreign assignment. In so doing, he knows about his own point of reference as he perceives the host country's situation and people. This establishes in his mind his own position, his own point of reference, in the configuration of the different local cultural norms and behavioral practices. Here, Varner and Palmer (2005) particularly argue the point thus, "the role of the individual, the importance of hierarchy, the importance of context in communication, and attitudes towards time and change."

Further, Varner and Palmer (2005) explain the multi phases in the going abroad experiences, "(1) potential expatriates are screened for personality characteristics ... contributing to expatriate success, (2) expatriates focus on developing a conscious self-awareness including their preferences, likes and dislikes, (3) potential expatriates study the other culture and their reaction to it, and (4) expatriates explore adaptation possibilities and strategies."

They further explain the internal processes of the individual expatriate manager or specialist, "Mental maps dictate how we react to events and people around us. In order to understand others, people need to explore their own cultural stereotypical thinking. Only after they have gained self-awareness can they develop a solid basis of cooperation." (Varner and Palmer, 2005)

\subsection{Individual Managerial Capabilities}

The US manager or specialist's managerial capabilities are important. These are capabilities as they are assessed in his home country context. These evaluations of managerial competence can be an important assessment for determining training content before the expatriate's departure to his foreign assignment.

In the approach of "multisource 360-degree feedback system", Luthans and Farner (2002) explain that it is "both a way to evaluate expatriate cultural training at behavioral and performance levels, as well as a way to develop expatriates to make them more effective once in the local culture." Further, they argue that their "expatriate management effectiveness questionnaire (EAEQ)" would draw worthwhile views of an expatriate, and, the "manager, subordinates and peers (hereafter referred to as "others") would be measured by items such as, "This person is able to answer my questions", and, "This person is technically competent." Four characteristics which are utilized in the EAEQ are: (1) Technical Competence: "This person is able to answer my question"; (2) Management Skills: "Solve specific problems and contribute to MNC's broader goals", and their ability to plan, coordinate work, schedule resources, try new ideas, control and follow-up; (3) Interpersonal Skills: "capability to get along with and work through others in a caring way", "caring emphatic concern for everyone", "listening to my ideas and concerns," "recognizes and gives credit to others who deserve it"; and (4) Leadership Effectiveness: "expatriates desire and need confidence to lead and work through people to accomplish assigned duties. ...", and "The person is loyal and committed to this organization". They further add a fifth and a sixth scale. They are: confidence/efficacy, and cultural fit. Confidence/efficacy, or, "how well one can execute courses of action required to deal with prospective situations", in a highly task- and context-specific manner.

Regarding the important issue of self-efficacy, it is worthwhile to mention the concept of "Know thyself" is the first step to plan for training of the individual US manager or specialist. It is worthwhile to have a healthy self-confidence attitude that reflects a strong and positive approach to life, and, to whole-heartedly face and solve any problem that he may come across. This approach does have a pre-emptive, a-priori impact upon expatriate performance in his foreign assignment. It is useful to review literature on self-efficacy because it is certainly the spirited approach of the expatriate that would see him through difficulties, initial and later on. 
Different studies on self-efficacy as well as self-monitoring indicate that these two important dimensions help in effective expatriate adjustment (Badura, 1992; Badura and Locke, 2003; and Gist and Mitchell, 1992). Self-efficacy is "a person's belief about his ability to perform a particular task effectively" (Maurer, Weiss and Barbeite, 2003). Self-efficacy has powerful effects upon learning a new task, and, consequently, the performance of the task itself (Gist and Mitchell, 1992). Further, self-efficacy can directly influence the adjustment and learning process by the following issues: (a) the choice of task and learning goals and activities, (b) the nature and amount of effort for the task, and (c) the level and nature of persistence to master the task despite its strangeness or difficulty (Badura, 1982). Also, in the same context, Shin, Morgeson and Campion (2007) explain that there can be Additional challenges on an individual expatriate in foreign assignments by way of the need for a more adjustment-oriented and achievement-oriented personality, in comparison to the challenges he had hitherto faced in his pristine domestic, US-based work and social experiences. Studies by Mendenhall and Oddon (1985) and Black (1990), cite the three dimensions for effective adjustment in foreign environment, "the relationship dimension; the perceptual dimension, and the self-dimension."

In the same context, Shin, Morgeson and Campion (2007) explain, "The relationship dimension refers to skills related to fostering of relationships with host nationals. For successful expatriate adjustment, it is essential to develop good relationships with host country nationals (HCNs). By maintaining proper relationships with HCNs expatriate workers are able to interact with them appropriately, to overcome problems and to perform assignments effectively".

Also, Cui, van den Berg and Jiang (1998), in reviewing additional studies, believe that there are, "significant relationships between communication competence, cultural empathy, social interaction, and cross-cultural adaptation. (Studies) suggested that relationship dimensions such as cultural empathy and interpersonal skills become important when dealing with cultural differences. A study found that better interpersonal skills were positively related to expatriates' adjustment to working and non-working environment in host countries".

In dealing with people of a particular culture, good communication is a key to effective managerial performance because it is through people that he accomplishes results. In a foreign assignment, the challenge is greater for the expatriate to analyze the organizational situation. Thus, communication, including a rudimentary working knowledge of the local language, would help him to better interact and foster good relationships with host country nationals in the foreign operations. By doing so, the expatriate will better acquaint himself of the operating situation and make more effective decisions. Good communication is the conduit through which he and his people can function as an integrated team. Language capability should be considered as an integral part of the communication skill enhancement training.

In the US, the people in the workplace use the US English language, and, the US manager or specialist is well versed in using it for his effective communication. However, if the host country's main commercial and working language is not English, Shin, Moregson and Campion (2007) suggest that in the foreign assignment, the expatriate executive would need additional communication skill capabilities. They explain thus, "The work demands for social and perceptual skills, reasoning ability and adjustment and achievement-orientation personality will be higher in non-English speaking countries than in English speaking countries." Their supporting rationale being, ". . . because language is an essential communication medium, expatriates may need more social skills in non-English speaking countries than in English speaking so they can develop favorable relationships with HCNs via social interactions."

\subsection{Stress Management and Problem Solving}

High stress can inhibit problem solving capability. As students in an exam hall of a difficult subject, our minds can go blank when we are very afraid. It takes time to regain composure before we can focus on answering the exam questions. Similarly, the expatriate must learn to manage stress, and, to tolerate moderately high levels of stress when he or she confronts strange situations. His or her stress, uncertainty, and anxiety feelings preclude him or her from correctly understanding and solving the work situations. His or her mentor can help him or her in managing his or her stress in the post-arrival stage.

Along similar lines of inquiries, Mendenhall and Oddou (1985), in their efforts to explore the issues of self-dimension, self-confidence and tolerance of stress in some depth, believe that, ". . (these) are closely related to individual's abilities and personality characteristics. This includes confidence in one's ability to deal effectively with foreigners and new surroundings." Xenophobia is the fear of anything foreign. "If anything is different, it must be wrong irrelevant or inferior," as an ethnocentric person may feel.

Similarly, Black, Gregersen, Mendenhall and Stroh (1999) state that a sudden exposure to unfamiliar surroundings would raise the level of the expatriate's stress that would significantly impair the expatriate's effectiveness as an 
executive or specialist in the foreign country situation. Similarly, studies on stress by Payne (1994), Mahoney et al (1998), Matthews and Wells (1988), Priester and Clum (1993) and Fraser and Tucker (1997) show that cognitive breakdowns, such as lapses of memory, reasoning, retrieval and perceptions in difficult situations, cause stress levels to go up. Further, increases in stress levels cause ineffectiveness in problem analyses and problem solving.

In such situations, the person does not correctly understand cause-effect relationships in a given problem situation. In this context, Shin, Morgeson and Campion (2007) state, "In turn, such perceived uncertainty may lead to intolerance of anomalies and incongruities and a strong need for explanation of cause-effect relationships. Thus, these kinds of reasoning ability would be particularly important set of cognitive abilities for expatriate work. This suggests that expatriate work will have higher reasoning ability requirements than domestic work because of stress, uncertainty, and anxiety associated with unfamiliar situations".

Shin, Morgeson and Campion (2007), in reviewing the body of knowledge on stress management, explain, “. . cognitive abilities as particularly important in stress-coping process. For example, studies have found a positive relationship between cognitive failures (failures of memory, reasoning and perception in everyday life) and stress susceptibility. In addition, it has been shown that problem-solving ability is negatively related to stress level. In a similar vein, uncertainty can be caused by an individual's inability to adequately structure or categorize information. In turn, such perceived uncertainty may lead to intolerance of anomalies and incongruities and a strong need for explanation of cause-and-effect relationships. This suggests that expatriate work will have higher reasoning ability requirements than domestic work because of stress, uncertainty, and anxiety associated with unfamiliar situations."

Caligiuri (2000) similarly "found that emotional stability was negatively related to the expatriate's desire to terminate their assignments." Other scholars (Harrison, Chadwick and Scales, 1996; Ones and Viswesvaran 1999; and Aycan, 1997) made similar findings about the important role that emotional stability (or equanimity) plays for the expatriate.

\subsection{The US Manager's Training Objectives}

The expatriate's training objectives are to build on the home country executive's capabilities. Such a training program may cover the generic expatriate for any international assignment, as well as the specific country assignment. When we view the specific country assignment, we narrow the scope and concentrate on the particular country culture and the particular foreign assignment's needs. The objectives include: managerial skills in the particular host country setting; people skills in the host country, working knowledge of local language and communication skills; a longer term perspective that makes the expatriate more tenacious to look for enduring solutions not quick fixes; quick and effective adaptation to local culture, organizational situation and country's operating situation; decision making in the local setting; the work ethic that promotes quick and upswing learning curve; and the knack for avoiding initial costly mistakes through mentoring and communication with trustworthy local nationals about appropriate executive conduct.

\subsection{The US Manager's Training Dimensions}

The expatriate's training must be tailor-made to focus on his unique individual needs and on his particular foreign assignment. These items of training include: knowledge about himself; self efficacy, self confidence, and a positive approach of surmounting any obstacle; better stress management and tolerance of uncertainty and anxiety; better adjustment-adaptability orientation; better achievement and goal accomplishment orientations; building better relationships through better empathy, sensitivity and understanding, and willingness to change one's behavior to accommodate host country's core values; knowledge of the task environment and social setting of the particular foreign assignment.

\section{Discussion and Recommendations for US Expatriate Training}

The objectives for the US expatriate should be first clearly formulated for a particular foreign assignment so that he or she may focus his or her training program for a specific foreign assignment. The expatriate's pre-departure training and post-arrival mentoring focus on preparing or conditioning him to be effective and appropriate in the host country and regional context.

The pre-departure training objectives for the expatriate should be based upon the unique needs of the expatriate, and, his or her particular foreign assignment. The expatriate's unique personal characteristics, past assignments and experience, skills, the nature of his or her openness to dissimilar cultures and foreign practices should be considered when formulating his or her training program. In addition, the considerations of his or her foreign assignment must be used to formulate his or her training program. The foreign assignment issues include the foreign country's details. These host country's details include: its history, culture, sub-cultures of the host country and its neighbors; life styles; 
infrastructure, economic, technical and business systems; social and business customs, protocol and etiquettes; and communication methods.

The expatriate's pre-departure training objectives may include:

1. Developing managerial leadership in the local host country context

2. Improving people skills in the host country society

3. Improving communication, including language, skills in the host country context

4. Developing a long term, strategic perspective for the foreign assignment so that the expatriate would want to "stay" with his assignment. This is even though the trend is now for expatriate assignments to be shorter rather than longer; a strategic, longer term horizon would enable an expatriate to have a greater feeling of being embedded in the local situation. This perspective is necessary for the expatriate to want to take greater ownership and tenacity to solve the difficult problems with lasting solutions

5. Improving flexibility and adaptation skills that would ease the transition to the host country cultural, logistical, industrial and commercial, and foreign remit environments

6. Developing a greater understanding of the decision making skills that build on insights of the foreign unit people and local knowledge of the business situation

7. Improving quick learning capability of local methods, customs and etiquette so as to avoid initial costly or embarrassing mistakes

8. Developing a better understanding of the host country's history and culture (and similarly of the neighboring countries of the regions) that would enable him to better understand the host country nationals and their neighbors.

The post-arrival mentoring is very important because the expatriate's learned content during the pre-departure training stage needs further guidance for its implementation. The early phases of the expatriate's post-arrival mentoring should be done by an experienced, mature international manager who has worked in the host or a nearby country. This approach would help the expatriate in the early months as the expatriate grapples with numerous issues and decision making challenges in the new unfamiliar surroundings and task environment. The expatriate also needs to balance or reconcile the MNC headquarters focus on the corporate and global perspective, on the one hand, with the host country environment situation, on the other hand (Zahra, 2001).

\section{Methods of Accomplishing the Training Objectives}

The US manager or specialist's pre-departure training program should focus on himself as a person dealing with his or her internal self, dealing with other people, and dealing the tasks of managing activities in the host country environment. Pre-departure training provides a good foundation for the US manager or specialist to gradually infuse into himself the elements of the working status of the foreign country; he better spiritually, mentally and emotionally prepared for going there and be ready for challenges there.

In dealing with his own personality, he can then become more effective as a person. These aspects of personality include his managing stress and anxiety. The unfamiliar work and non-work situations in his foreign assignment course increased perceived environmental uncertainty and personal anxiety and stress. The expatriate has to become facile in the cause-effect relationship in the host country context. Pre-departure training would condition him about how host country nationals make decisions, interact and conduct business. The expatriate should build his competence of problem solving through improved cognitive capability. This calls for a fuller awareness of the nature of host country's business customs, methods and processes. Cognitive capability in this context is important and refers to the expatriate building a better repertoire of his reasoning and perception in everyday life, with a quick learning curve that relies on good memory and retrieval process. This approach would enable him to feel that he has a good command of his task environment, an important state of emotion that drives down his or her personal stress.

His self-efficacy and self confidence are important for him to be effective. He may have a strong track record as an effective manager in the domestic environment, yet he or she needs to further his confidence in himself for meeting the greater challenge in the unfamiliar task environment. Together with greater tolerance of stress, anxiety and uncertainty because of unfamiliar environment, he needs to be a more optimistic and confident person. He should have a firm mind set that radiates endless confidence that he can and will solve all problems in the foreign assignment, some of which may take a longer time. The more familiar he is with the problems of his foreign 
assignment before he leaves for the foreign assignment, the better will be his grasp to deal with the realities after his arrival in the host country.

For a more effective adjustment to the host country environment, he himself or she herself must be emotionally stable. His equanimity and staying cool and steady even in different or unfamiliar problem situations will be critical for him to solve problems. He must know himself better; know his or her own ways of dealing with his or her challenges, and his preferences and fears. He must develop a plan to improve his dealing with these emotions. He must self-monitor his improvement plan. Even when he is down, emotionally, he still must have an optimistic posture. He must develop a wider range of flexibility of his personal behavior and personal adjustment to varying social, task and logistical situations. His studying of the conditions - work and non-work - of the host country would be necessary in building and retaining such composure.

Effective expatriate performance would also depend upon his continuously building himself to be better on each of these dimensions:

1. Better adjustment-oriented personality that emphasizes improved personal emotional stability, self-control and self-monitoring, personal flexibility, and a greater capacity to tolerate uncertainty, unfamiliarity, stress and anxiety.

2. Better achievement-oriented personality that relies on: (i) tenacity to focus on clearly set task and personal goals by overcoming obstacles; (ii) stronger initiative-ness to solve problems in the unfamiliar foreign situation; (iii) sustained higher personal motivation that relies on "cold" heat rather than hot emotion to solve problems through people, (iv) longer-term, strategic perspective of his foreign assignment that is built on the premise that he will stay with the problems wand not run away from them, (and a clear mandate from the MNC headquarters to this effect would provide him with the necessary support); and (v) proactive and entrepreneurial focus for exploring newer opportunities that would benefit the foreign subsidiary beyond the short term.

His ability to accomplish performance through the local people is critical (particularly critical in the initial phases of his foreign assignment) to his expatriate leadership role. In this regard, he must continuously develop better communication skills, including a working knowledge of the local commercial language. He needs to become a better listener, be better at building cultural empathy and inter-personal skills, and be better in social interaction for working as a team player. His people skills will have to be even better in the foreign assignment than in his domestic assignment. When he is in the foreign assignment he would be to rely even more on the local people for gathering, sorting, interpreting information and for guidance in alternative courses or actions. He should not attempt to chart the detailed actions in isolation, but only in conjunction with local people. His people skills will be useful again as he improves their capabilities through training them. Further, if his foreign assignment is in a country where the working language is not English, then he would have to be even better in his social and perceptual skills, his reasoning ability, the adjustment and achievement orientations of his personality for him or her to overcome the language barrier.

\section{Conclusions}

An expatriate from advanced countries such as US must pursue pre-departure training on: self motivation and self efficacy; stress management; cross cultural adaptation, communication motivation and leadership; build local work and social relationships; seek effective skills of decision making in teams in the host country culture. Post-arrival mentoring must focus on dealing with stress and uncertainty; social situations in work and non-work environments; decision making in teams; and complex or unfamiliar problems in the task environments. Effective expatriate training is a prerequisite for effective expatriate performance.

US managers and specialists initially at least may face more obstacles challenges, uncertainty, strangeness, and stress than to domestic managers. The initial stress upon arrival in the host country is because of the cultural differences, reduced situation understanding and coping capability, ineffective adaptation and problem solving, and reduced communication fluency and work relationship competence. The initial months, at least, are marked by a greater need for mentoring for dealing with local, culturally different people situations, such as, leadership, supervision, motivation, conflict, leadership and group dynamics.

The training goals and approaches should focus on the general as well as the country specific objectives for the US manager and specialist to accomplish the following dimensions of pre-departure training and post-arrival mentoring programs:

\section{- Improved managerial leadership}


- Improved people skills

- Improved and effective communication skills

- Improved longer term, strategic perspective

- Improved and better adaptation-oriented personality

- Improved and effective decision-making in the foreign environment

- Improved and faster learning curve, together with better retention

- Improved understanding of the host country culture, background and logistics

No training or mentoring program is complete unless it also addresses the US manager or specialist's unique, individual self. The US manager or specialist expatriate must focus on and re-configure the following characteristics and dimensions of his own personality and his own self:

- Improved managing with his own personal stresses, strains and anxieties and environmental uncertainties even though the local environments seem very strange to him

- Improved emotional intelligence and emotional stability through better self-efficacy and self-monitoring for improved self-flexibility, self-direction, self-initiated, and self-motivation

- Improved and realistic self-esteem and self-regard, self-reliance and self-confidence, with a strong problem-solving, goal achievement orientations

- Improved adjustment oriented and achievement oriented personality (to take initiative, setting desirable goals and tenaciously pursuing them, modifying, followed by improved implementation and review processes)

- Improved skills for professional, industry, governmental and organizational networking and communication and people interactions through empathy, clarity of communication and social interaction

- Improved social networking skills and sustained building of relationships so that he continuously improves, through the local people, his insights of the host country culture, history and methods of working, approaches of operating in the local task and social environments.

Because of the greater expatriate challenge he needs training before departure to his foreign assignment, and, mentoring after his arrival in the host country. Both, pre-departure training and post-arrival mentoring would help prevent initial embarrassing mistakes and also help self adjustment so that the expatriate can better concentrate on his goal accomplishment process.

The pre-departure training focuses on developing (a) expatriate's personal capabilities (self-confidence, self-motivation, self-discipline and monitoring, stress management, goal orientation and constancy of purpose despite difficulties and uncertainties); (b) building relationships through good communication and empathy in the local context; and (c) improving his or her problem analyses and solving skills in different countries.

US managers and specialists would benefit by focusing upon their effective pre-training and post-arrival mentoring. US organizations should provide the needed resources and help them in the processes. US managers and specialists would face in their intense training in dealing with the very different cultural and operating conditions in his foreign assignment. Even though he may be a quick and a good learner in the US home environment, he must develop better skills for quick learning and better recall and better application of what he has learned. In this way, he would effective when he starts his foreign assignment. It would be likely that he would avoid initial embarrassing mistakes.

The US manager and specialist should develop his own customized training programs and approaches, with the help of his organization, to better address the issues of his foreign assignment, such as: (a) better cross-cultural adjustments and flexibility and cross cultural adaptation to local working and non-working or social environments, (b) managing with his own stress wrought from unfamiliarity, and (to him) even strange, uncertainty and anxiety of the unfamiliar situation, (c) self-reliance and self-confidence building process for dealing with different situations and still function in difficult and unfamiliar surroundings with knowledge of operant cause-effect relationship, (d) building his equanimity and emotional stability, and, self-efficacy, self-monitoring, flexibility, adaptability and motivation that would ensure better adjustment so that he may better concentrate on the task, (e) build sustained focus and tenacity, strong personal and organizational goals achievement-orientation, taking initiative and focusing on task effectiveness, (f) continuous improvement orientation such that he is continuously improving his managerial processes, including skills such as: goals setting, decision-making, communication, supervisory, problem solving in 
order to be more effective in his work and social interactions, (g) continuously improve his own mental mapping process and cognitive reasoning and information processing skills and emotional assessment skills for effectively performing in totally diverse and newer environments.

\section{References}

Acyan, Z. (1997). Acculturation of expatriate managers: A process model of adjustment and performance. In A. Acyan (Ed.), New Approaches to Employee Management (Vol. 4, 1-40). Greenwich, CT: JAI Press.

Badura, Albert. (1982). Self-efficacy mechanisms in human systems. Journal of Applied Psychology, 37, 122-147.

Badura, Albert, \& E. A. Locke. (2003). Negative self-efficacy and goal effects revisited. Journal of Applied Psychology, 88, 87-89. https://doi.org/10.1037/0021-9010.88.1.87

Black, J. S., H. B. Gregerson, M. E. Mendenhall, \& L. K. Stroh. (1999). Globalizing People Through International Assignment. Reading, MA: Addison-Wesley.

Brewster, C., \& J. Pickard. (1994). Evaluating expatriate training. International Studies of Management and Organization, 24(3), 18-35. https://doi.org/10.1080/00208825.1994.11656635

Caliguiri, P. M. (2000). The big five personality characteristics as predictors of expatriate's desire to terminate the assignment and supervisor-rated performance. Personnel Psychology, 53(1), 67-88. https://doi.org/10.1111/j.1744-6570.2000.tb00194.x

Chang, Wei-Wen. (2005). Expatriate training in international non-governmental organizations: A model for research. Human Resource Development Review, 4(4), 440-463. https://doi.org/10.1177/1534484305281035

Chao, G. T., \& Y. J. Sun. (1977). Training needs for expatriate adjustment in People's Republic of China. In A. Aycan (Ed.), New Approaches to Employee Management (Vol. 4). Greenwich, CT: JAI Press.

Cui, G., S. Vanden Berg, \& W. Jiang. (1998). Cross-cultural adaptation and ethic communication: Two structural equation models. The Howard Journal of Communications, 9(1), 69-85. https://doi.org/10.1080/106461798247122

Frazer, K. P., \& C. M. Tucker. (2007). Individualization, stress and problem-solving abilities of college students. Journal of College Student Development, 38, 461-467.

Gist, M. E., \& T. R. Mitchell. (1992). Self-efficacy: A theoretical analysis of its determinants and malleability. Academy of Management Review, 17, 183-211.

Harrison, J. K., M. Chadwick, \& M. Scales. (1996). The relationship between cross-cultural adjustment and personality variables of self-efficacy and self-monitoring. International Journal of Intercultural Relations, 20(2), 167-188. https://doi.org/10.1016/0147-1767(95)00039-9

Li-Yueh Lee, \& Robert Croker. (2006). A contingency model to promote the effectiveness of expatriate training. Industrial Management and Data Systems (Wembley), 106(8), 1187-1195. https://doi.org/10.1108/02635570610710827

Luthans, Kyle W., \& Steve Farner. (2002). Expatriate development: The use of 360-degree feedback. The Journal of Management Development (Bradford), 21(9-10), 780-795. https://doi.org/10.1108/02621710210448048

Maurer, T. J., E. M. Weiss, \& F. G. Barbiete. (2003). A model of involvement in work-related learning and developmental activity: The effects of individual, situational and motivational age variables. Journal of Applied Psychology, 88(4), 707-724. https://doi.org/10.1037/0021-9010.88.4.707

Mendenhall, M. E., \& G. Oddou. (1985). The dimensions of expatriate acculturation: A review. Academy of Management Review, 10(1), 39-47.

Mendenhall, M. E., \& Gunter K. Stahl. (2000). Expatriate training and development: Where do we go from here? Human Resource Management (Hoboken), Summer/Fall, 36(2), 3, 251.

Oddou, G. R. (1991). Managing your expatriates: What the successful firms do. Human Resource Planning, 14(4), 301-308.

Ones, D. S., \& C. Viswesvaran. (1999). Personality determinants in the prediction of aspects of expatriate job success. In A. Aycan (Ed.), New Approaches to Employee Management (Vol. 4). Greenwich, CT: JAI Press.

Payne, R. (1994). Individual differences in the study of occupational stress. In C. L. Cooper and R. Payne (Eds.), Causes, Coping, and Consequences of Stress at Work (pp. 209-232). New York, NY: John Wiley \& Sons. 
Petranek, G. F. (2004). Global human resource development: The four C approach. Human Resource Development Quarterly, 15(2), 249-252. https://doi.org/10.1002/hrdq.1100

Priester, M. J., \& G. A. Clum. (1993). Perceived problem-solving ability as a predictor of depression, hopelessness, and suicide ideation in a college population. Journal of Counseling Psychology, 40(1), 79-85. https://doi.org/10.1037/0022-0167.40.1.79

Prud'homme van Reine, Peter, \& Fons Trompenaars. (2000). Invited reaction: Developing expatriates for the Asia-Pacific region. Human Resource Development Quarterly (San Francisco), Fall, 11(3), 237-244. https://doi.org/10.1002/1532-1096(200023)11:3<237::AID-HRDQ3>3.0.CO;2-N

Selmer, Jan. (2000). A quantitative needs assessment technique for cross-cultural work adjustment training. Human Resource Development Quarterly (San Francisco), Fall, 11(3), 269-282. https://doi.org/10.1002/1532-1096(200023)11:3<269::AID-HRDQ5>3.0.CO;2-6

Selmer, Jan, \& Jakob Lauring. (2011). Expatriate academics: Job factors and work outcomes. International Journal of Manpower, 32(2), 194-210. https://doi.org/10.1108/01437721111130206

Shin, Shung J., Frederick P. Morgeson, \& Michael A. Campion. (2007, January). What you do depends on where you are: Understanding how domestic and expatriate work requirements depend upon cultural context. Journal of International Business Studies, 38(1), 64-83. https://doi.org/10.1057/palgrave.jibs.8400247

Suutari Vesa, \& David Burch. (2001). The role of on-site training and support expatriation: Existing and necessary host-company practices. Career Development International (Bradford), 6(6), 298-312. https://doi.org/10.1108/EUM0000000005985

Tung, Rosalie. (1982). Selection and training procedure of US, European and Japanese multinationals. California Management Review, 25(1), 57-71. https://doi.org/10.2307/41164993

Varner, Iris L., \& Teresa M. Palmer. (2005). Role of cultural self-knowledge in successful expatriation. Singapore Management Review, 27(1), 1-26.

Wynne, Michael. (2006, October). The hidden cost of expatriate executives. Global Cosmetic Industry, 174(10), 49-50.

Yeh-Yun Lin, Carol, \& Yu-Chen Wei. (2005, August). An Eastern and SME version of expatriate management: An empirical study of small and medium enterprises in Taiwan. The International Journal of Human Resource Management (London), 16(8), 14-31.

Zahra, Shaker A. (2001). Entrepreneurship in the Multinational Corporation: The effects of corporate and local contexts. Academy of Management Proceedings, G1-G6. https://doi.org/10.5465/APBPP.2001.6133082 